\title{
O DISCURSO DA CONTRADIÇÃO EM MACHADO DE ASSIS
}

\author{
Maria Lúcia Fernandes Guelfi \\ Faculdade de Ciências e Letras da UNESP - Araraquara
}

O sentido machadeano dos sigilos da alma se articula em muitos casos com uma compreensão igualmente profunda das estruturas sociais.

(Antônio Cândido)

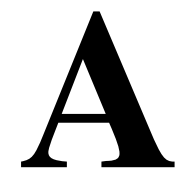

obra de Machado de Assis revela rigoroso esforço criador, permanente exercício da imaginação e dos meios de expressão na busca de uma profundidade que resiste até hoje às mais diversas leituras críticas. Silviano Santiago ${ }^{1}$ demonstra como certas estruturas primárias dessa obra se desarticulam e se rearticulam, cada vez mais complexas e sofisticadas, à medida que seus textos se sucedem cronologicamente. A consciência crítica de Machado, a lucidez com que se dedica ao ofício de escritor, pode ser claramente percebida no prefácio do romance Ressurreição:

No extremo verdor dos anos presumimos muito de nós, e nada, ou quase nada, nos parece (...) impossível. Mas o tempo, que é bom mestre, vem diminuir tamanha confiança (...). Com o tempo, adquire a reflexão o seu império, e eu incluo no tempo a condição do estudo, sem o qual o espírito fica em perpétua infância. Dá-se então o contrário do que era dantes. Quanto mais versamos os modelos, penetramos as leis do gosto e da arte, compreendemos a extensão da responsabilidade, tanto mais se nos acanham as mãos e o espírito, posto que isso mesmo nos esperte a ambição, não já presunçosa, senão refletida. (...) Cada dia que passa me faz conbecer melhor o agro destas tarefas literárias, - nobres e consoladoras, é certo, - mas difíceis quando as perfaz a consciência. ${ }^{2}$

${ }^{1}$ SANTIAGO, 1978, p. 29-48. (Debates, 155)

2 ASSIS, 1986, v. 1, p. 116. Grifos meus. 
Ao assumir o seu ofício de escritor, como tarefa árdua de uma consciência crítica sempre vigilante, Machado revela uma inteligência que, observando atentamente o contexto social, consegue entender - com espantosa perspicácia para a época - a importância dos seus códigos de representação. Muito antes das modernas teorias cognitivas, ${ }^{3}$ que pressupõem o construtivismo, segundo o qual toda percepção, todo julgamento, todo conhecimento é uma construção, ${ }^{4}$ Machado de Assis percebeu o que a muitos espíritos é difícil de compreender ainda hoje, ou seja, que os modelos literários - as leis do gosto e da arte - são produtos culturais, tanto quanto os demais sistemas de comunicação e de representação social. O império da reflexão e a condição do estudo fizeram dele profundo conhecedor de tais sistemas, fornecendo-lhe também subsídios para desenvolver habilidades excepcionais de manipulação dos códigos de representação literária.

Sem o respaldo dos estudos semióticos e das teorias sobre a cultura dos simulacros, Machado de Assis empreendeu uma análise da sociedade brasileira por meio de acurado estudo de seus sistemas

\footnotetext{
${ }^{3}$ Entre as mais significativas teses que trabalham nessa linha estão as gestaltistas, para as quais, a percepção do mundo é um processo de organização, de ordenamento de dados sensoriais para torná-los conformes com certa quantidade de grandes categorias e de "leis" do cérebro - a apreensão do real estaria relacionada à descoberta de estruturas profundas que correspondem às próprias estruturas mentais (AUMONT, 1993, 91).

${ }^{4}$ Construção elaborada por meio de confrontação de hipóteses, fundamentadas em esquemas mentais - alguns inatos, outros provenientes da experiência com os dados fornecidos pelos órgãos dos sentidos (AUMONT, 1993, 91). Segundo Siegfried Schmidt, os teóricos construtivistas empregam a expressão para "designar processos que levam à formulação de concepções de realidade, de modo algum arbitrários ou independentes da interação com o mundo circundante, mas baseados em condições biológicas, cognitivas e socioculturais concretas, às quais os indivíduos socializados estão submetidos em seu mundo social". Sendo mais uma imposição do que um controle de nossa parte, geralmente não nos damos conta da construtividade do nosso mundo circundante. (SCHMIDT, 1994, 115)
} 
de significação. Embora lhe faltasse o instrumental teórico, surgido após o aparecimento de algumas ciências e áreas do conhecimento desenvolvidas no Século XX - como a lingüística, a semiótica, a antropologia, a psicanálise, a teoria da comunicação, a sociologia -, Machado realiza uma desconstrução crítica de estruturas mentais e de esquemas de conhecimento, que funcionavam como paradigmas científicos e filosóficos privilegiados naquele momento, fazendo o mesmo com os códigos de linguagem e de comportamento próprios das elites brasileiras da época.

O resultado foi esta obra densa e complexa que, ao longo das décadas, tem resistido a uma pluralidade de leituras críticas, apoiadas nos mais diferentes modelos teóricos. Explorando ao máximo as convenções de linguagem que permitem leituras plurissignificativas, acolhendo a multiplicidade de vozes discursivas - a "polivalência do verbo literário" -, a obra de Machado permite que cada grupo e cada época encontrem nela, como diz Antônio Cândido, "as suas obsessões e as suas necessidades de expressão". ${ }^{5}$

Sucessivas gerações de leitores e críticos brasileiros foram encontrando níveis diferentes nesta obra, o que redundou na exaltação do seu autor pelos mais diversos motivos, muitos deles até contraditórios. Quando Machado de Assis ainda era vivo, a unanimidade da crítica o consagrava pelo estilo irônico e refinado. Ao contrário das descrições minuciosas de detalhes chocantes das obras naturalistas, seus contos e romances, construídos a partir da elaboração paciente de subentendidos, alusões e eufemismos, não feriam as exigências do decoro e do bom-gosto.

Se o estilo elegante e comedido, apoiado em mensagens moralizantes e na leitura da Bíblia, fez a fama de Machado no começo do século, outros aspectos de sua produção literária seriam valorizados nas décadas seguintes, em decorrência da adoção de novos instrumentais teóricos. A partir dos anos trinta, apoiada em

${ }^{5}$ CÂNDIDO, 1977, p. 18. 
critérios psicológicos, a crítica rompe o véu da elegância, que recobre a estrutura paradoxal de suas narrativas, e descobre a ambigüidade, a perplexidade e o senso de absurdo que permeiam a ficção machadeana. Uma ficção dirigida sobretudo a um leitor paciente e perspicaz, atento aos vazios e avessos do texto, capaz de uma leitura mais complexa e menos ingênua do que aquela realizada por seus contemporâneos.

O peso da filosofia e da sociologia no desenvolvimento do pensamento brasileiro dos anos quarenta foi responsável por novas inflexões do discurso crítico sobre a obra de Machado de Assis. A partir de então, ora a crítica exalta os aspectos metafísicos dessa obra, ora discute a sua alienação ou o seu engajamento em relação à realidade social brasileira. ${ }^{6}$

A espantosa independência de Machado de Assis em relação ao que Antônio Cândido denomina como "modas literárias" não se deve apenas por alguma espécie de alheamento em relação a estilos e doutrinas consagrados na época. Mais do que isso, o estilo literário de Machado de Assis consiste numa exploração sistemática da contradição, como estratégia de desconstrução dos códigos literários, filosóficos e científicos vigentes. Ele não se mantém alheio aos modismos, mas se utiliza deles para desmascarar os jogos de dominação e poder que estão por trás dos discursos consagrados pelas classes e grupos dominantes.

É do próprio interior desses mesmos discursos das elites, explorando a linguagem elegante, estabelecida pelos padrões do bom-senso e do bom-gosto, que este ficcionista vai rasurar, com ironia, os códigos de significação privilegiados do sistema social brasileiro, subvertendo os hábitos requintados da burguesia e os esquemas lógicos do pensamento científico. Em outras palavras, a crítica à sociedade burguesa não se limita a descrições superficiais de costumes ou exaustivos inventários de mazelas públicas e

${ }^{6}$ CÂNDIDO, 1977, p. 21. 
privadas, mas se concentra numa exposição de como funcionam os próprios esquemas de dominação dessa burguesia.

Aperfeiçoando a cada obra a técnica da ironia, sua principal arma na exploração das contradições sociais, Machado não se põe ingenuamente na posição de um autor que deseja melhorar a sociedade, como se ocupasse um lugar neutro, de fora. Ao contrário, assume a linguagem das elites, colocando-se como parte integrante do mesmo sistema que satiriza. Desse modo rompe com o protótipo do escritor realista-naturalista que, do alto de um saber ilustrado, se sente responsável pelo progresso científico e moral da sociedade como um todo. Essa postura parcial de Machado ao assumir o lugar de onde fala, que se revela principalmente na preferência pela focalização interventiva, freqüentemente autodiegética, é um dos aspectos de sua obra que nos parece contemporâneo.

Outro aspecto igualmente contemporâneo, em Machado de Assis, é a sua percepção complexa do que seja realidade social. Não obstante trabalhe dentro do projeto realista/naturalista, a ficção de Machado de Assis opera uma desconstrução desse projeto e amplia fronteiras, desterritorializando conceitos e desfazendo as oposições impostas pelo sistema de pensamento racionalista como realidade/ ficção, verdade/fantasia, contexto social/imaginário, razão/loucura.

Ao contrário da visão simplista que se revela em muitos escritores de sua época, que viam a realidade como algo palpável, um referente concreto, externo ao sujeito, passível de ser retratado por uma linguagem transparente e neutra, Machado parece conceber a realidade como resultado de uma interação, em diversos níveis, de aspectos internos e externos ao indivíduo, aproximando-se com esta percepção de muitos teóricos contemporâneos. Siegfried J. Schmidt, por exemplo, abandona completamente os esquemas de pensamento que indagam sobre uma realidade dos objetos percebidos como "concretos" e sobre a verdade das declarações sobre tal realidade, por julgar que mesmo as nossas percepções mais espontâneas do mundo sensível já são mediadas pelos padrões de conhecimento e de comunicação que nos foram internalizados por nossas condições sócio-culturais: 
Os construtivistas (...) abandonam justamente esse tipo de indagação. As alusões feitas às condições empíricas, altamente complexas, sob as quais as produções de sentido (construções da realidade) cognitivas e comunicativas operam, deveriam explicitar que as construções da realidade estão atreladas às condições operativas internas dos sistemas cognitivos e comunicativos, a partir das quais o mundo circundante é tratado e processado. (...) Ao operar com dados sensoriais do meioambiente, os indivíduos verificam dentro dos limites de conceitos de avaliação internos e esquemas de valor seu "conteúdo de realidade". Essas operações complexas são (...) condicionadas biológica, psíquica, social e culturalmente. ${ }^{7}$

Ao trabalhar com diferentes níveis de realidade, embaralhando a experiência interior e externa dos personagens, Machado aponta a fragilidade das fronteiras entre o mundo psíquico e o contexto social. O conto "O Espelho" é um brilhante exemplo de como esses níveis de realidade se misturam. O protagonista, fascinado por sua imagem exterior - o prestígio que a farda de alferes lhe confere diante das pessoas -, fica "tomado" por esta imagem, que se torna a sua própria alma. Ao olhar-se no espelho sem a farda sua figura esfumada é apenas uma sombra. Ao vestir a farda seus contornos voltam a se refletir no espelho. Imaginário e real se interpenetram na concepção de mundo machadeana. Problematizando a ilusão referencial, Machado confere ao projeto realista/naturalista uma configuração complexa, que não contraria as teorias construtivistas do conhecimento e da percepção, surgidas nas últimas décadas: o que o revela, aos olhos da crítica atual, como um excepcional escritor contemporâneo.

Atrelada à compreensão de Machado a respeito da interação entre o que se poderia denominar grosso modo de "realidade interior" e "realidade exterior", verifica-se a compreensão do sistema social - e também do literário - como permanente jogo de interesses, regulado por códigos culturalmente construídos. No romance Quincas Borba, fica evidente que, embora o dinheiro seja uma das

${ }^{7}$ SCHMIDT, 1994, p. 120. 
principais motivações para os atos dos personagens, não é o único deles. O protagonista, mesmo tendo recebido elevada soma de herança, não sobrevive às ciladas que lhe armam Palha e Sofia. Por não dominar os códigos de comportamento impostos pelo sistema, não chega a perceber que está sendo usado pelo casal.

Machado ridiculariza o excesso de racionalismo da época. As investigações sobre os limites entre razão e loucura - empreendida de maneira primorosa no conto "O Alienista" -, entre verdade e imaginação - tal como aparece no livro Dom Casmurro - rasuram o discurso cientificista, instaurando a dúvida e a cumplicidade entre narrador e leitor, ao contrário do que pregavam os cânones da representação realista.

Principal expoente da literatura realista no Brasil, Machado acaba por se colocar na contingência paradoxal de um autor cujo principal alvo de crítica não se localiza num suposto referente externo - como queriam os sistematizadores do movimento - mas nos próprios procedimentos pregados pelo realismo/naturalismo. É sobretudo quando rasura o modelo estético consagrado pela burguesia nos fins do Século XIX, que Machado empreende a crítica ao sistema social construído por essa mesma burguesia. Seu estilo "em palimpsesto" ${ }^{\circ}$ opera uma permanente contradição, que obriga o leitor a reconstruir constantemente a sua visão de mundo.

O positivismo, impondo às narrativas o objetivo de buscar a verdade de cada um, induzia à dissecação dos motivos que impulsionam a ação dos personagens. Decifrar, iluminar, esclarecer são procedimentos obsessivos entre os escritores realistas. Fascinados pela intimidade dos personagens, o objetivo dos narradores consiste em desnudar personalidades, revelando a causalidade complexa das relações sociais. Explorando métodos de

\footnotetext{
${ }^{8}$ A imagem de palimpsesto é evocada por Luís Costa Lima para designar a "composição que oferece uma pista socialmente aceitável, para que, de seu avesso, entre as frases interrompidas, surjam outras linhas, que, no entanto, não deveriam ser claramente legíveis, porque são virulentas" (LIMA, 1981, 104).
} 
observação e análise, os naturalistas buscavam sempre determinadas causas para o comportamento dos personagens: causas naturais, como o clima, a raça e o temperamento, ou causas culturais, como o meio e a educação. ${ }^{9}$ Esse determinismo reduzia a área de perspectiva da instância narrativa e a liberdade dos personagens.

Machado de Assis diverte-se desmontando cada uma dessas jogadas preestabelecidas pelas regras literárias, trabalhando no sentido de desmascarar os mecanismos desse modelo de prosa. O motivo da fatalidade, por exemplo, que configura o determinismo, é corroído a todo instante pela sagaz ironia dos narradores. Em Dom Casmurro, um advogado sexagenário esforça-se por reunir argumentos para provar a traição da mulher com seu melhor amigo. Valendo-se do determinismo na construção dessa argumentação, o protagonista tem por único objetivo persuadir o leitor sobre a sua verdade: "e tu concordarás comigo; se te lembras bem da Capitu menina hás de reconhecer que uma estava dentro da outra, como a fruta dentro da casca". ${ }^{10}$

Seduzido pelo discurso do advogado, que se apóia não numa investigação dos fatos, mas sobre o raciocínio apriorístico, que manipula os dados, como no trecho acima, onde utiliza uma causa natural para explicar o comportamento humano, o leitor sente-se compelido a julgar Capitu, esquecendo-se de que o próprio título da obra - Dom Casmurro - deveria indicar que o centro das atenções de Machado era a personalidade do protagonista. A narração em primeira pessoa se constrói basicamente sobre as impressões confusas, cristalizadas na memória de um homem obcecado pelo ciúme. Entretanto o próprio narrador lança a dúvida sobre os métodos deterministas de análise, ao alertar o leitor, em vários momentos, a respeito de sua péssima memória: "Não, não, a minha memória não é boa. (...) Como eu invejo os que não

${ }^{9}$ BOSI, 1982, p. 188.

${ }^{10}$ ASSIS, 1986, v.1, p. 944. 
esqueceram a cor das primeiras calças que vestiram! Eu não atino com a das que enfiei ontem. Juro só que não eram amarelas porque execro essa cor; mas isso mesmo pode ser olvido e confusão". ${ }^{11}$ Para tornar ainda menos confiável o seu relato, enfatiza-se outra informação importante sobre a prodigiosa imaginação do narrador: "A imaginação foi a companheira de toda a minha existência, viva, rápida, inquieta, alguma vez tímida e amiga de empacar, as mais delas capaz de engolir campanhas e campanhas correndo". ${ }^{12}$

A construção de um discurso verídico, segundo os moldes do realismo e do naturalismo, implica algumas convenções específicas para a construção da narrativa. Além da objetividade de um discurso "transparente", sem quaisquer referências ao processo da enunciação, propõe-se também o apagamento completo das convenções do discurso, para aumentar a ilusão de uma reconstrução do real. As descrições detalhadas e abundantes reforçam as informações que sugerem a existência de referenciais externos. As longas descrições de cenários e ambientes, - o flash-back recordações, resumo, análise do passado -, e certos recursos especiais com que o narrador antecipa o clímax, por meio de profecias e maldições, valendo-se de personagens excepcionais como loucos, profetas, amigos de infância, etc, respondem à necessidade de assegurar a confiança nas informações.

Contrariando as lições de Flaubert, sistematizador da teoria do "romance que narra a si próprio", ${ }^{13}$ Machado cultiva livremente o elíptico, o incompleto, o fragmentário, fazendo seus ousados narradores intervirem constantemente no relato. As pistas logo se evidenciam como contrapistas, as profecias são desmentidas. Desse

${ }^{11}$ ASSIS, 1986, v.1, p. 870.

${ }^{12}$ ASSIS, 1986, v.1, p. 350.

13 "Esforço-me por entrar no espartilho e seguir uma linha reta geométrica: nenhum lirismo, nada de reflexões, ausente a personalidade do autor", dizia Flaubert a respeito de seu método de trabalho. (Correspondência, 1-2-1852) 
modo não deixa o leitor esquecer que as verdadeiras causas que movem a narrativa estão na vontade e astúcia de um narrador, assim como, no palco social, também as causas dependem sobretudo da vontade daqueles que detêm o domínio sobre os instrumentos de dominação e de manipulação.

\section{Referências Bibliográficas}

AUMONT, Jacques. A imagem. Campinas: Papirus, 1993.

ASSIS, Machado de. Obra completa, 2 v. Rio de Janeiro: Nova Aguilar, 1986.

BOSI, Alfredo. História concisa da literatura brasileira. 3.ed. São Paulo: Cultrix, 1982.

CÂNDIDO, Antônio. Esquema de Machado de Assis. Vários escritos. São Paulo: Duas Cidades, 1977, p. 14-32.

LIMA, Luiz Costa. Sob a face de um bruxo. Dispersa demanda. Rio de Janeiro: Francisco Alves, 1981, p. 57-122.

SANTIAGO, Silviano. Retórica da verossimilhança. Uma literatura nos trópicos. São Paulo: Perspectiva, 1978, p. 29-48. (Debates, 155)

SCHMIDT, Siegfrield. Construtivismo na pesquisa dos meios de comunicação: conceitos, conseqüências. Palavra, Rio de Janeiro, n. 2, p. 111-137, 1994. 


\section{Resumo}

Este ensaio pretende mostrar como Machado de Assis, embora historicamente incluído no Realismo, desconstrói as mais importantes convenções literárias adotadas pelos autores desse período: a causalidade e a teleologia da narrativa, a objetividade e a neutralidade dos relatos, o cientificismo do discurso são constantemente desacreditados pela sagaz ironia de seus narradores. Rasurando fronteiras e desmascarando os modos de representação realista, as narrativas de Machado de Assis questionam a oposição entre alguns conceitos como realidade e ficção, verdade e fantasia, contexto social e imaginário, razão e loucura. A ambigüidade e a contradição que emergem de seus textos instalam a suspeita na mente de seus leitores e os obrigam a reconstruírem constantemente sua visão de mundo. Assim, Machado de Assis problematiza a ilusão referencial, o que confere à sua obra uma excepcional contemporaneidade.

\section{Abstract}

This paper attempts to show how Machado de Assis, although historically included in Realism, deconstructs the most important literary conventions adopted by the authors of that period: the narrative causality and teleology, the objectivity and neutrality of the accounts, the scientism of the speech are constantly discredited by the sagacious irony of his narrators. By erasing boundaries and unmasking the realistic modes of representation, Machado de Assis' narratives discuss the opposition between some concepts like reality and fiction, truth and fantasy, social context and imaginary, reason and madness. The ambiguity and contradiction that come up out his texts install the suspicion in the readers mind and compel them often to rebuild their vision of the world. So, Machado de Assis problematizes the referential delusion, what gives his work a exceptional contemporaneity. 